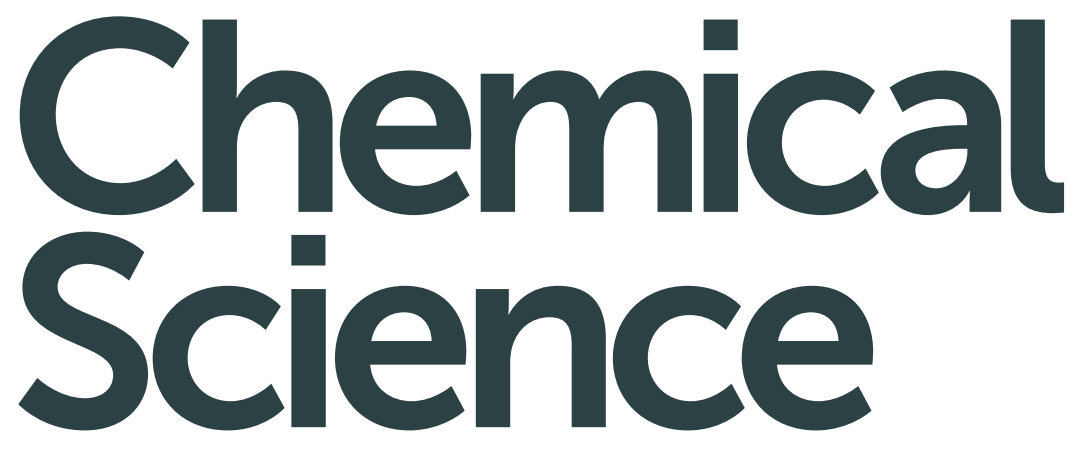

rsc.li/chemical-science

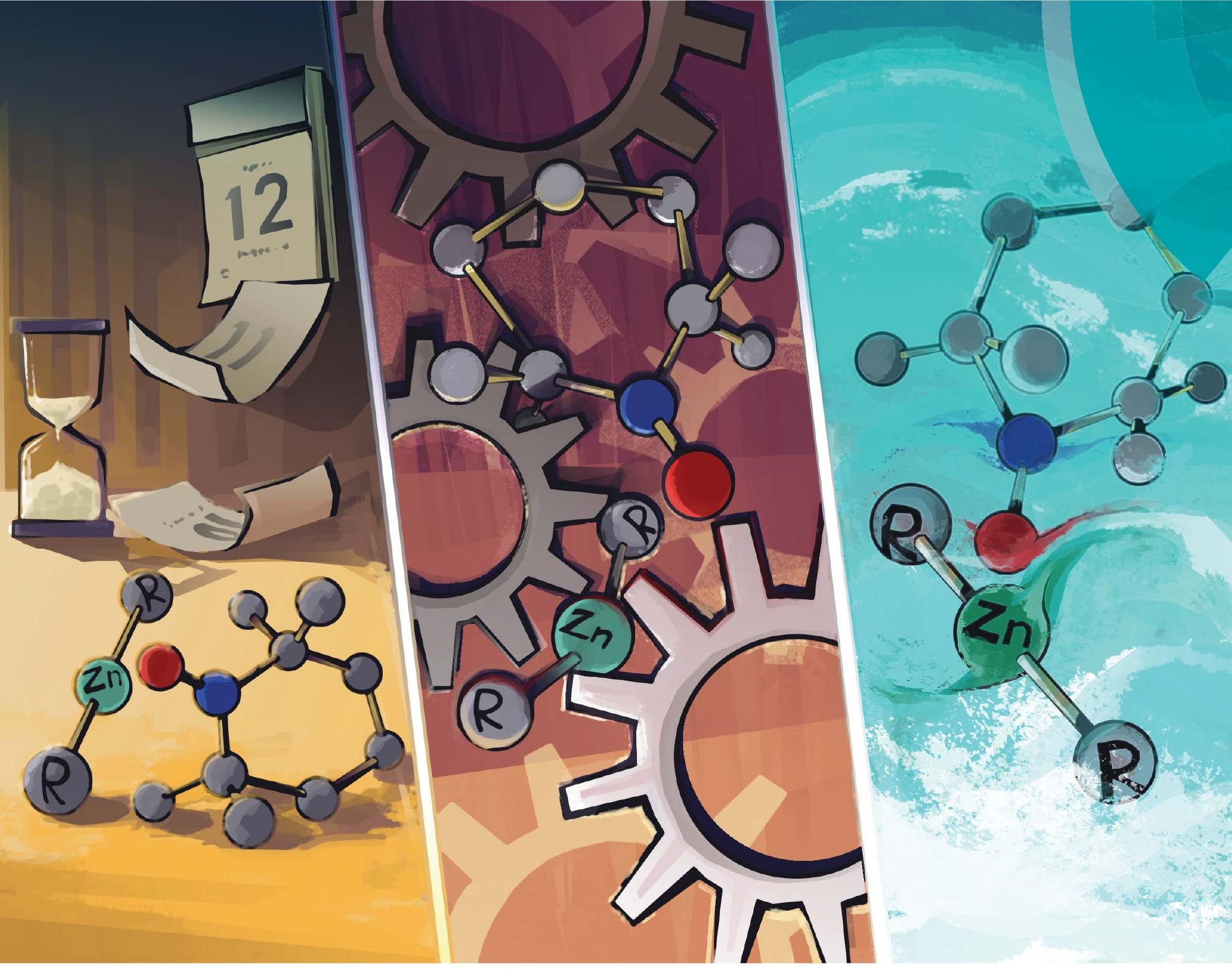

ISSN 2041-6539 
Check for updates

Cite this: Chem. Sci., 2019, 10, 7149

๑ All publication charges for this article have been paid for by the Royal Society of Chemistry

Received 21st March 2019

Accepted 16th June 2019

DOI: $10.1039 / c 9 s c 01396 b$

rsc.li/chemical-science

\section{Mechanochemical and slow-chemistry radical transformations: a case of diorganozinc compounds and TEMPO $\uparrow$}

\author{
Krzysztof Budny-Godlewski, (D) a Iwona Justyniak, (DD b Michał K. Leszczyński iD b \\ and Janusz Lewiński iD *ab
}

From the green chemistry perspective, molecular solid-state transformations conducted under mild conditions are of great interest and desirability. However, research in this area lacked popularity in the previous century, and thus progressed slowly. In particular, the application of radical reactions in solidstate chemistry has been hampered by several long-standing challenges that are intrinsically associated with the apparent unpredictable nature of radical chemistry. We present a comparative study of model mechanochemical, slow-chemistry and solution radical reactions between TEMPO and homoleptic organozinc compounds (i.e., di-tert-butylzinc and diphenylzinc). In the case of the $t \mathrm{Bu}_{2} \mathrm{Zn} / \mathrm{TEMPO}$ reaction system only a dimeric diamagnetic complex $\left[t \operatorname{BuZn}(\mu-\mathrm{TEMPO} *]_{2}\right.$ is obtained in yields slightly varying with the method chosen. In contrast, when TEMPO is mixed with diphenylzinc in a $2: 1$ molar ratio a novel paramagnetic Lewis acid-base adduct [ $\left.\left[\mathrm{Ph}_{2} \mathrm{Zn}\left(\eta^{1}-\mathrm{TEMPO}\right)\right] \cdot \mathrm{TEMPO}\right]$ is isolated in high yields regardless of the applied methodology. This adduct is also formed in the slow-chemistry process when TEMPO is gently mixed with $\mathrm{Ph}_{2} \mathrm{Zn}$ in a $1: 1$ molar ratio and left for two weeks at ambient temperature. Within the next week the reaction mixture gives in high yield a diamagnetic dinuclear compound $[\mathrm{PhZn}(\mu-\mathrm{TEMPO})]\left[\mathrm{PhZn}\left(\mu_{2}-\eta^{1}: \eta^{1}-\mathrm{TEMPO}\right)\right]$ and biphenyl. The analogous reaction conducted in toluene results in a much lower conversion rate. The reported results open up a new horizon in molecular solidstate radical transformations.

\section{Introduction}

The rational development of solid-state reactions is one of the objectives of the green chemistry movement. Notably, in the previous century research on molecular solid-state reactions mediated by mechanical forces progressed slowly which was aptly annotated by Braga and Grepioni: "Although research work in this area has never stopped, it has also lacked popularity and has remained confined to a few connoisseurs". ${ }^{1}$ Only the last decade has witnessed a true renaissance of mechanochemistry $^{2-5}$ applications of which include organic ${ }^{6-10}$ and organometallic synthesis, ${ }^{\mathbf{1 1 - 1 4}}$ polymer chemistry, ${ }^{\mathbf{1 5}, \mathbf{1 6}}$ and materials science (e.g. in the preparation of MOFs, ${ }^{17,18}$ perovskites for solar cells ${ }^{19-22}$ or nanomaterials). ${ }^{3,23-26}$ In some cases mechanical stress can support electron transfer ${ }^{27}$ or cause

${ }^{a}$ Faculty of Chemistry, Warsaw University of Technology, Noakowskiego 3, 00-664 Warsaw, Poland. E-mail: lewin@ch.pw.edu.pl; Fax: +48 22 6282741; Tel: +48 22 2347315

${ }^{b}$ Institute of Physical Chemistry, Polish Academy of Sciences, Kasprzaka 44/52, 01-224 Warsaw, Poland

$\dagger$ Electronic supplementary information (ESI) available: Characterization data of new products: the NMR, EPR, IR spectra, extended PXRD diffractograms and crystallographic data. CCDC 1550886-1550888. For ESI and crystallographic data in CIF or other electronic format see DOI: $10.1039 / \mathrm{c} 9 \mathrm{sc} 01396 \mathrm{~b}$ homolytic bond cleavage and in consequence the formation of radicals. A textbook example of a radical solid-state chemistry phenomenon, which was already noted in ancient Greece, is the attraction between rubbed amber and some small objects. ${ }^{28}$ Only in 1967 Urbański revealed the formation of radicals on the surface of ground amber. ${ }^{29}$ The formation of radicals has also been observed upon mechanically induced reactions in polymeric materials. ${ }^{\mathbf{3 0 , 3 1}}$ Grzybowski and co-workers demonstrated that these mechanoradicals can be responsible for static charge stabilization, and thus, polymers intentionally doped with radical scavengers (inter alia free stable radicals) are less vulnerable to static charging. ${ }^{32-34}$ Despite these seminal pioneering discoveries solid-state radical reactions have remained an underdeveloped area of research.

Even though mechanochemistry is slowly becoming a routine solid-state synthesis tool, knowledge on the intimate mechanistic details is very limited. ${ }^{26,35,36}$ Remarkably, an emerging field of slow-chemistry (mild condition reactions occurring in the solid-state without an external stimuli) ${ }^{37}$ or accelerated aging reactions (i.e., solid-state transformations where reaction rates are enhanced by the presence of solvent vapour $^{38}$ nicely complements and enriches solid-state processes, and may turn out to be an area to help better understand mechanochemical reactions. Slow-chemistry 
reactions are widely observed in nature, e.g. biomineralization, pearl formation or mineral neogenesis, and only recently have these natural processes been mimicked in synthetic

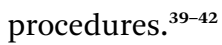

Herein we present unprecedented solvent-free slow-chemistry and mechanical force triggered radical transformations involving solid homoleptic organozinc compounds and an intentionally added free stable nitroxyl radical, (2,2,6,6-tetramethylpiperidin-1-yl)oxyl (TEMPO). Very recently, in contrast to common beliefs, ${ }^{43}$ our group and independently Stephan's group demonstrated that in solution TEMPO is non-innocent towards $\mathrm{Et}_{2} \mathrm{Zn}^{\mathbf{4 4 , 4 5}}$ and $\left(\eta^{5}-\mathrm{C}_{5} \mathrm{Me}_{5}\right)_{2} \mathrm{Zn},{ }^{46}$ respectively, and smoothly induces radical transformations triggered by singleelectron transfer $(\mathrm{SET})^{47}$ from the $\mathrm{Zn}-\mathrm{C}$ bond to TEMPO, to afford organozinc complexes incorporating TEMPO anions. We were wondering whether TEMPO will also remain non-innocent towards homoleptic diorganozinc compounds in the solid-state and to this end we chose di-tert-butylzinc $\left(t \mathrm{Bu}_{2} \mathrm{Zn}\right)$ and diphenylzinc $\left(\mathrm{Ph}_{2} \mathrm{Zn}\right)$ solid homoleptic organometallics with versatile properties and reactivity. ${ }^{4-50}$ The solid-state reactions were commenced with comparative solution phase investigations. Remarkably, while in the case of the $t \mathrm{Bu}_{2} \mathrm{Zn} / \mathrm{TEMPO}$ system either wet chemistry or mechanochemical and slow-chemistry transformations provided essentially the same outcome, the character of the products of the $\mathrm{Ph}_{2} \mathrm{Zn}$ /TEMPO system depends significantly on the stoichiometry of the reaction and the selected synthetic methodology.

\section{Results and discussion}

\section{Comparative investigations in solution}

Initially, when a toluene solution of $t \mathrm{Bu}_{2} \mathrm{Zn}$ was treated with an orange toluene solution of TEMPO (2 equiv.) at $-78{ }^{\circ} \mathrm{C}$, an instantaneous decolourization took place. Standard work-up of the post-reaction mixture afforded colourless crystals of a diamagnetic dimeric complex $\left[t \operatorname{BuZn}\left(\mu-\mathrm{TEMPO}^{*}\right)\right]_{2} \quad\left(\mathbf{1}_{2}\right)$ (Fig. 1a, TEMPO* stands for the TEMPO anion) and TEMPO- $t$ Bu as the primary products. The formation of $\mathbf{1}_{2}$ is likely triggered by an incipient $t \mathrm{Bu}_{2} \mathrm{Zn} / \mathrm{TEMPO}$ adduct followed by an intramolecular SET from the $\mathrm{Zn}-t \mathrm{Bu}$ bond to TEMPO, and TEMPO$t \mathrm{Bu}$ results from the subsequent release of a $t \mathrm{Bu}$ radical and its recombination with the second TEMPO molecule. ${ }^{51}$ In this case we were not able to isolate the anticipated paramagnetic Lewis acid-base $\mathrm{R}_{2} \mathrm{Zn}$ (TEMPO) adduct due to the high reactivity of homoleptic zinc alkyls towards TEMPO. Remarkably, the respective paramagnetic adduct was isolated from a similar reaction with $\mathrm{Ph}_{2} \mathrm{Zn}$. Clearly, $\mathrm{Ph}_{2} \mathrm{Zn}$ is less prone to react as a SET reagent, and moreover the $\mathrm{Ph}_{2} \mathrm{Zn} / \mathrm{TEMPO}$ system appeared also sensitive to the molar ratio of the reagents and reaction time. A 1:1 mixture of the starting materials was dissolved in toluene and stirred at room temperature for an hour and then cooled to $-26^{\circ} \mathrm{C}$. Within 24 hours yellow crystals of a supramolecular complex $\left[\left[\mathrm{Ph}_{2} \mathrm{Zn}\left(\eta^{1}\right.\right.\right.$-TEMPO $\left.\left.)\right] \cdot \mathrm{TEMPO}\right]$ (2 - TEMPO) deposited in moderate yield. Compound $2 \cdot$ TEMPO is composed of a paramagnetic Lewis acid-base adduct $\left[\mathrm{Ph}_{2} \mathrm{Zn}\left(\eta^{1}\right.\right.$-TEMPO $\left.)\right]$ (2) with a hydrogen-bonded TEMPO molecule (Fig. 1b). Interestingly, a prolonged (two weeks) reaction between $\mathrm{Ph}_{2} \mathrm{Zn}$ and 1 equiv. of TEMPO conducted at ambient temperature in toluene generated a new diamagnetic dinuclear complex $\left[\operatorname{PhZn}\left(\mu-\mathrm{TEMPO}^{*}\right)\right]\left[\operatorname{PhZn}\left(\mu_{2}-\eta^{1}: \eta^{1}-\mathrm{TEMPO}^{*}\right)\right] \quad$ (3, Fig. 1c) (yield ca. 35\%) as well as biphenyl ( $\mathrm{PhPh}$ ) resulting from homocoupling of the $\mathrm{Ph}^{*}$ radicals. Remarkably, the $\mathrm{Ph}$ ' radicals do not recombine with TEMPO molecules on this occasion as we did not observe the signals characteristic of TEMPO-Ph in the ${ }^{1} \mathrm{H}$ NMR spectrum of the post-reaction mixture.

To clarify the factors determining the formation of the paramagnetic complex $2 \cdot$ TEMPO and the diamagnetic complex 3 , we performed the reaction of $\mathrm{Ph}_{2} \mathrm{Zn}$ with 2 equiv. of TEMPO in a manner analogous to that of the equimolar system (for details, see the Experimental procedures). In this case the SET process was suppressed and 2-TEMPO was isolated essentially quantitatively. Undoubtedly, a key aspect of the $\mathrm{Ph}_{2} \mathrm{Zn} / \mathrm{TEMPO}$ reaction system is the reduction of TEMPO to its anionic form by $\mathrm{Ph}_{2} \mathrm{Zn}$ (with the subsequent coupling of the formed $\mathrm{Ph}^{\text {* }}$ radicals to yield $\mathrm{PhPh}$ ) only for the $1: 1$ mixture while a higher amount of TEMPO inhibits the SET step (for details see Fig. S22 in the ESI†).

\section{Crystal structure analysis}

Compounds $\mathbf{1}_{2}, \mathbf{2} \cdot$ TEMPO and 3 were characterized by NMR spectroscopy and single-crystal X-ray diffraction, and additionally the paramagnetic character of 2 - TEMPO was confirmed by EPR spectroscopy. Compounds $\mathbf{1}_{2}$ and 3 show sharp ${ }^{1} \mathrm{H}$ NMR resonances characteristic of the zinc bonded organic groups and the TEMPO* anion, while the NMR spectrum of $2 \cdot$ TEMPO confirms its paramagnetic character (Fig. S1-S8 in the ESI $\dagger$ ). The diffusion ordered NMR spectroscopy (DOSY) experiments show that $\mathbf{1}_{2}$ and 3 most likely exist as monomers in solution (for details, see Table S1 in the ESI $\dagger$ ). Remarkably, the solution and solid-state EPR spectra of $2 \cdot$ TEMPO show one set of signals analogous to that observed for the free TEMPO radical (see Fig. S13 and S14 $\dagger$ ).

X-ray crystal structure analysis showed that the molecular structure of the tert-butyl-zinc derivative $\mathbf{1}_{2}$ (Fig. 1a) is essentially analogous to the previously reported diamagnetic ethylzinc derivative $\left[\operatorname{EtZn}\left(\mu \text {-TEMPO }{ }^{*}\right)\right]_{2},{ }^{46}$ and comprises bridging $\mu$ TEMPO* ligands and a planar $\mathrm{Zn}_{2} \mathrm{O}_{2}$ ring $(\mathrm{Zn} 1-\mathrm{O} 1=1.939(3) \AA$ and $\left.\mathrm{Zn} 1-\mathrm{O}^{\prime}{ }^{\prime}=1.964(3) \AA\right)$. In turn, the relevant phenyl-zinc derivative 3 crystallizes as an asymmetric dimer that contains a rarely encountered mix of coordination $\mu$-O- and $\mu-\eta^{1}: \eta^{1}-\mathrm{NO}-$ modes of the anionic TEMPO* ligands (Fig. 1c). ${ }^{52}$ Two threecoordinate zinc atoms are bridged by $\mu$-O-TEMPO* and $\mu-\eta^{1}: \eta^{1}$ NO-TEMPO* units, thus forming a slightly bent five-membered [ZnOZnNO] ring (Zn1-O1 = 1.916(3) Å, O1-Zn2 = 1.943(3) Å, $\mathrm{Zn} 2-\mathrm{N} 2=2.078(3) \AA$ A, N2-O2 = 1.441(4) $\AA$, and O2-Zn1 = $1.898(2) \AA$ ).

In the paramagnetic adduct $2 \cdot$ TEMPO, one TEMPO radical coordinates to the zinc centre in an $\eta^{1}$-mode $(\mathrm{Zn} 1-\mathrm{O} 1=$

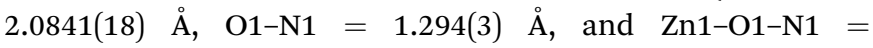
$\left.143.50(17)^{\circ}\right)($ Fig. 1b). The second TEMPO molecule interacts by hydrogen bonding involving the oxygen atom and the $\mathrm{C}-\mathrm{H}$ bond of one $\mathrm{Zn}$-bonded $\mathrm{Ph}$ group $(\mathrm{H} 5-\mathrm{O} 2=2.323(9) \AA$ A, O2-N2 = $1.288(3) \AA$, and $\left.\mathrm{H} 5-\mathrm{O} 2-\mathrm{N} 2=86.517(13)^{\circ}\right)$ and the observed 


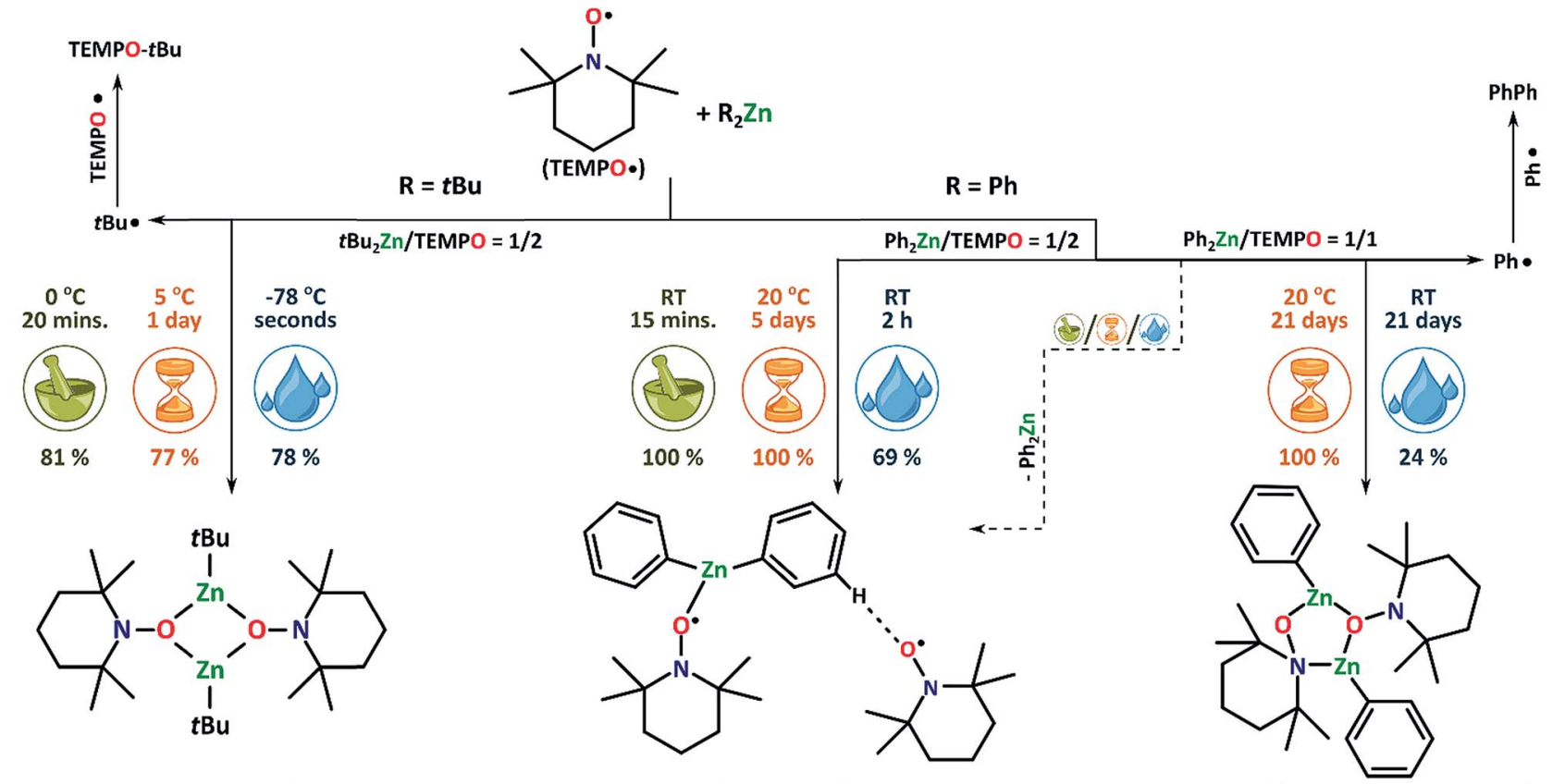

(a) $\left[\operatorname{tBuZn}\left(\mu \text {-TEMPO }{ }^{*}\right)\right]_{2}$ $\left(1_{2}\right)$

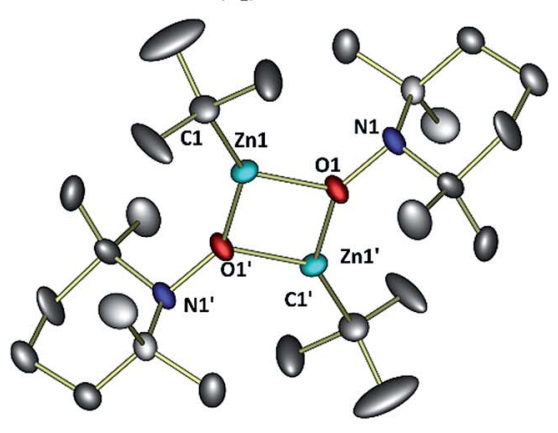

(b) $\left[\mathrm{Ph}_{2} \mathrm{Zn}\left(\eta^{1}\right.\right.$-TEMPO) $\bullet$ TEMPO] $(2 \bullet$ TEMPO)

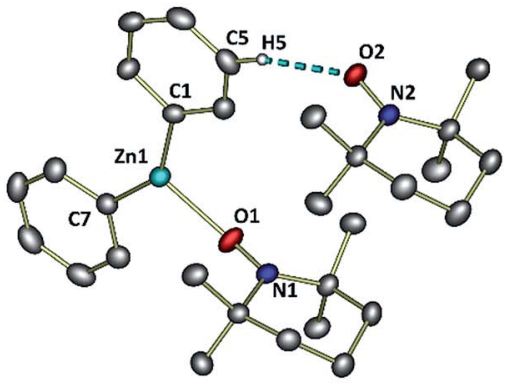

(c) $[\operatorname{PhZn}(\mu$-TEMPO $)]\left[\operatorname{PhZn}\left(\mu_{2}-\eta^{1}: \eta^{1}-\right.\right.$ TEMPO $\left.\left.^{*}\right)\right]$ (3)

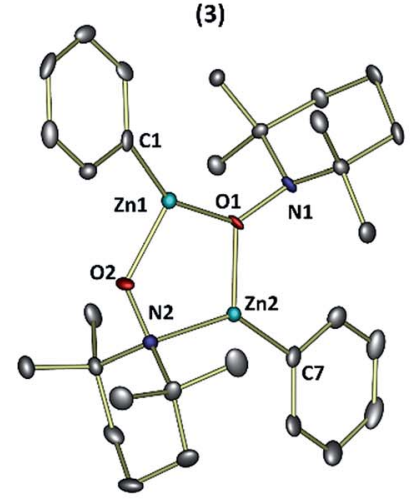

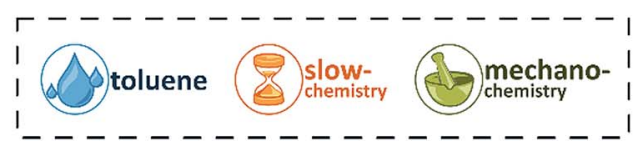

Fig. 1 Unprecedented variety of outcomes of the solid-state and wet reactions of TEMPO with $t B u_{2} Z n$ and $P h_{2} Z n:(a)[t B u Z n(\mu-T E M P O *)]_{2}\left(1_{2}\right)$, (b) $\left[\left[\mathrm{Ph}_{2} Z n\left(\eta^{1}-\mathrm{TEMPO}\right)\right] \cdot \mathrm{TEMPO}\right](2 \cdot \mathrm{TEMPO})$, and (c) $[\mathrm{PhZn}(\mu-\mathrm{TEMPO} *)]\left[\mathrm{PhZn}\left(\mu_{2}-\eta^{1}: \eta^{1}-\mathrm{TEMPO}\right)\right]$ (3).

hydrogen-bonding interaction torsion angle $\mathrm{N} 2-\mathrm{O} 2 \cdots \mathrm{H} 5-\mathrm{C} 5=$ $45.227(20)^{\circ}$ is similar to the calculated $\mathrm{N}-\mathrm{O} \cdots \mathrm{H}-\mathrm{C}$ torsion angle $\left(45^{\circ}\right)$ for the $\mathrm{CH}_{3} \mathrm{CN} / \mathrm{TEMPO}$ system..$^{53}$ The zinc atom occupies a site within a trigonal-planar arrangement of the oxygen and carbon atoms $(\mathrm{C} 1-\mathrm{Zn} 1-\mathrm{C} 7=145.61(12), \mathrm{C} 1-\mathrm{Zn} 1-\mathrm{O} 1=$ $112.8(1)^{\circ}$, and $\left.\mathrm{O} 1-\mathrm{Zn} 1-\mathrm{O} 7=101.4(1)\right)$ with the $\mathrm{Zn} 1-\mathrm{O} 1$ bond length markedly longer than that observed for the $\mathrm{Zn}-\mathrm{O}$ bond in zinc complexes incorporating an external anionic $\eta^{1}$-TEMPO* ligand ( $c f$. the $\mathrm{Zn}-\mathrm{O}$ of $1.854(6)$ in $\left.\left[\mathrm{Zn}\left(\mathrm{TEMPO}^{*}\right)_{2}\right]_{2}\right){ }^{46}$ To the best of our knowledge, the adduct 2 is the first isolated and structurally characterized simple Lewis acid adduct of TEMPO with an organometallic molecule. ${ }^{54}$ The revealed hydrogen-bond interaction between the free TEMPO molecule and the $\mathrm{Zn}$ bonded Ph group as well as a vast number of other non-covalent interactions observed in the solid-state structure of 2 -TEMPO (see Fig. S27 $\dagger$ ) are likely responsible for an increased stability of 2 -TEMPO in the solid-state (note that 2 -TEMPO does not transform into 3 in the solid-state, vide infra).

\section{Reactions in the solid-state}

Equipped with the above knowledge about the reactivity of TEMPO towards $t \mathrm{Bu}_{2} \mathrm{Zn}$ and $\mathrm{Ph}_{2} \mathrm{Zn}$ in solution, we performed analogous reactions with these reagents in the solid-state. The progress of both slow-chemistry and mechanochemical reactions was monitored using PXRD analysis (for extended diffractograms see Fig. S9-S12 $\dagger$ ) and additionally confirmed by ${ }^{1} \mathrm{H}$ NMR spectroscopy; all operations were conducted under an argon inert gas atmosphere.

We revealed that both slow- and mechanochemical reactions take place in the case of the $t \mathrm{Bu}_{2} \mathrm{Zn} / \mathrm{TEMPO}$ system, and 
selectively afford $\mathbf{1}_{2}$ and TEMPO- $t \mathrm{Bu}$ in high yield (Fig. 2). The mechanochemical reaction involving grinding $t \mathrm{Bu}_{2} \mathrm{Zn}$ with 2 equiv. of TEMPO with a glass rod at $0{ }^{\circ} \mathrm{C}$ occurs within circa 20 minutes (Fig. 2b). In the slow-chemistry reaction, $t \mathrm{Bu}_{2} \mathrm{Zn}$ was gently mixed with 2 equiv. of TEMPO and then stored at $5{ }^{\circ} \mathrm{C}$ under an inert gas atmosphere and in this case the reaction required circa 24 hours for completion (Fig. 2c).

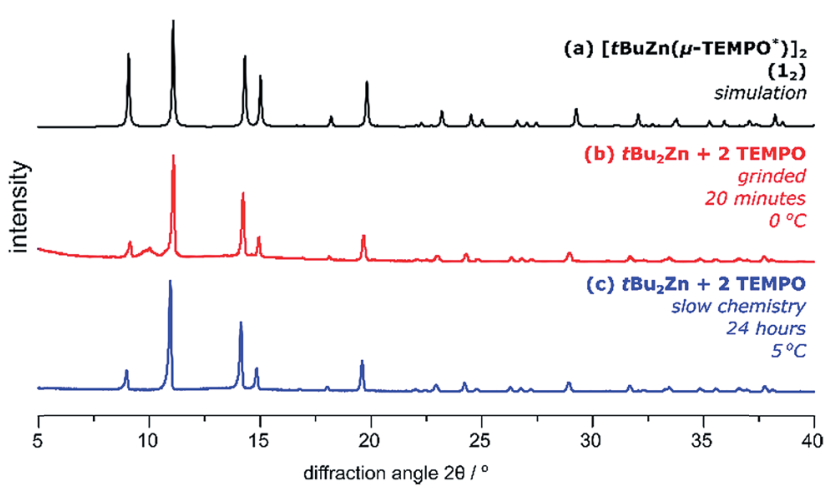

Fig. 2 The PXRD patterns for the reactions of TEMPO with $t \mathrm{Bu}_{2} \mathrm{Zn}$ : (a) the simulated PXRD spectrum of $1_{2}$, (b) the mixture of $t \mathrm{Bu}_{2} \mathrm{Zn}$ and 2 equiv. of TEMPO ground with a glass rod for 20 minutes at $0{ }^{\circ} \mathrm{C}$ and (c) the mixture of $t \mathrm{Bu}_{2} \mathrm{Zn}$ and 2 equiv. Of TEMPO gently mixed and stored at $5^{\circ} \mathrm{C}$ for $24 \mathrm{~h}$.

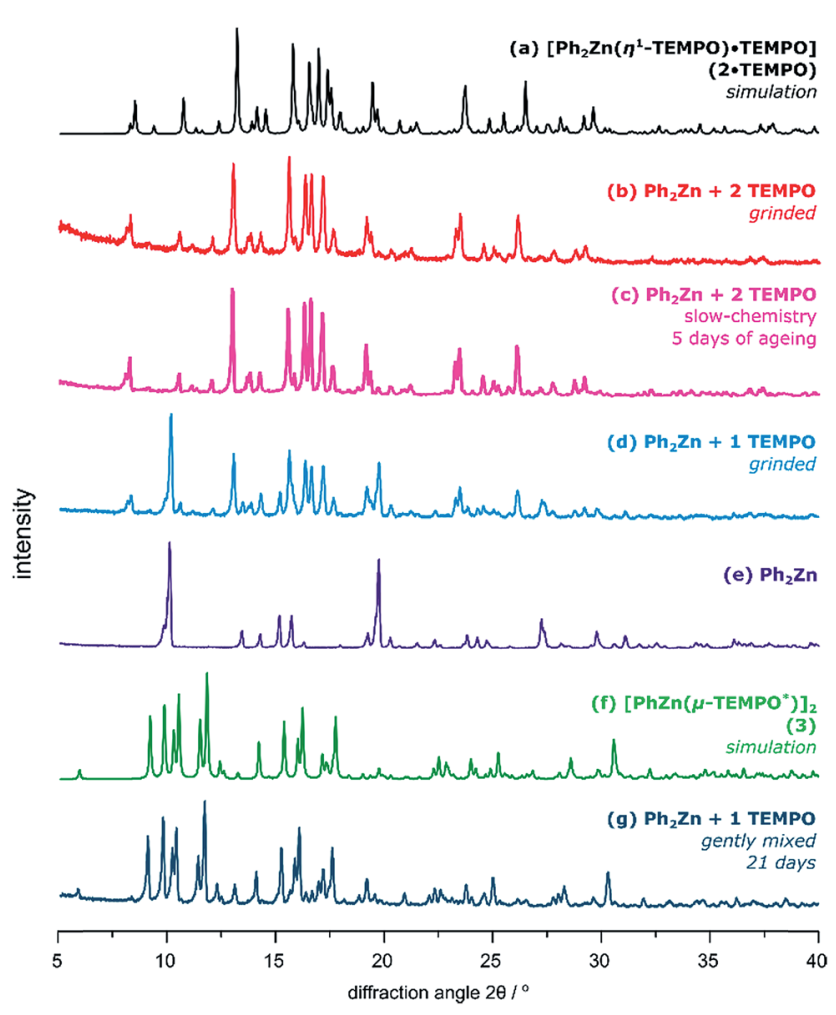

Fig. 3 The PXRD patterns of various reaction systems involving TEMPO and $\mathrm{Ph}_{2} \mathrm{Zn}$ : (a) the simulated PXRD spectrum of 2.TEMPO, (b) $\mathrm{Ph}_{2} \mathrm{Zn}$ ground with 2 equiv. of TEMPO, (c) $\mathrm{Ph}_{2} \mathrm{Zn}$ gently mixed with 2 equiv. of TEMPO and stored under an inert gas atmosphere at $20^{\circ} \mathrm{C}$ for 5 days, (d) $\mathrm{Ph}_{2} \mathrm{Zn}$ ground with 1 equiv. of TEMPO, and (e) $\mathrm{Ph}_{2} \mathrm{Zn}$. (f) The simulated PXRD spectrum of 3 and (g) $\mathrm{Ph}_{2} \mathrm{Zn}$ gently mixed with 1 equiv. of TEMPO stored at $20^{\circ} \mathrm{C}$ for 21 days.
Strikingly, transformations involving $\mathrm{Ph}_{2} \mathrm{Zn}$ and TEMPO proceed entirely differently than in the case of the $t \mathrm{Bu}_{2} \mathrm{Zn} /$ TEMPO system (Fig. 3). Grinding $\mathrm{Ph}_{2} \mathrm{Zn}$ with 1 equiv. of TEMPO at ambient temperature for over 15 minutes gives a mixture of the paramagnetic adduct $2 \cdot$ TEMPO and unreacted $\mathrm{Ph}_{2} \mathrm{Zn}$ as judged by the PXRD analysis (Fig. $3 \mathrm{~b}$ ). However, when $\mathrm{Ph}_{2} \mathrm{Zn}$ is ground with 2 equiv. of TEMPO, then 2 -TEMPO is obtained selectively as the only product (Fig. 3c). Regardless of the grinding conditions (molar ratio of substrates, prolonged time, and higher frequency of milling), no trace of the $\mathbf{3}$ phase was observed in the PXRD pattern of the postreaction powder.t What is more, the pure compound 2 -TEMPO does not transform into the diamagnetic compound 3 even after over 6 months of aging $\left(20^{\circ} \mathrm{C}\right.$ and inert gas atmosphere).

The slow chemistry reactions involving $\mathrm{Ph}_{2} \mathrm{Zn}$ and TEMPO in various molar ratios are more subtle. The paramagnetic adduct 2 -TEMPO is obtained selectively within ca. 5 days of aging (20 ${ }^{\circ} \mathrm{C}$ ) of a mixture consisting of $\mathrm{Ph}_{2} \mathrm{Zn}$ gently mixed with 2 equiv. of TEMPO (Fig. 3d). No further transformation of $2 \cdot$ TEMPO was observed in the solid state even after over 6 months of aging. In the case of the equimolar mixture of $\mathrm{Ph}_{2} \mathrm{Zn}$ and TEMPO the slow-chemistry reaction proceeds differently and consists of two distinguishable steps. In the first step, the reaction yields an intermediate mixture of 2 -TEMPO and $\mathrm{Ph}_{2} \mathrm{Zn}$, which in the second step quantitatively transforms into an equimolar mixture of 3 and PhPh (Fig. 4). Moreover, the evolution of PXRD diffractograms of the equimolar mixture of $\mathrm{Ph}_{2} \mathrm{Zn}$ and TEMPO over time depends on the way the substrates were initially mixed (ground or gently mixed). The PXRD analysis of the initially ground substrate mixture reveals patterns characteristic of 2 -TEMPO and $\mathrm{Ph}_{2} \mathrm{Zn}$. Then after 21 days of aging the PXRD patterns evolve into that characteristic of 3 (patterns characteristic of $\mathrm{PhPh}$ are not observed but its formation was

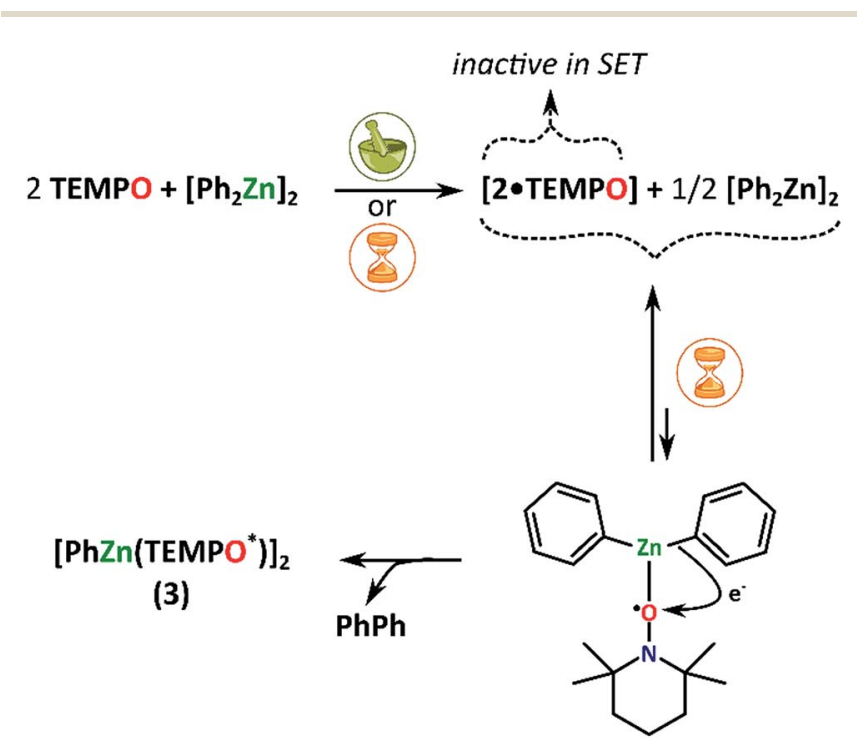

(2)

active in SET

Fig. 4 Proposed mechanism of the reaction of TEMPO with $\mathrm{Ph}_{2} \mathrm{Zn}$ (1: 1 molar ratio) in the solid-state. 
confirmed by ${ }^{1} \mathrm{H}$ NMR spectroscopy). In contrast, the gently mixed substrate mixture affords an intermediate mixture of $2 \cdot$ TEMPO and $\mathrm{Ph}_{2} \mathrm{Zn}$ within 7 days of aging and then within the next 14 days transforms into 3 and $\mathrm{PhPh}$.

The above results indicate that the solid-state equimolar mixture of $\mathrm{Ph}_{2} \mathrm{Zn}$ and TEMPO initially smoothly transforms into a 2 -TEMPO supramolecular complex while half the amount of $\mathrm{Ph}_{2} \mathrm{Zn}$ remains intact. Subsequently, the mixture of $2 \cdot$ TEMPO and $\mathrm{Ph}_{2} \mathrm{Zn}$ transforms into 3 in the slow-chemistry process. Remarkably, this transformation is not observed for the pure phase 2-TEMPO complex under either mechanochemical or slow-chemistry conditions. Thus, at this stage of studies it is reasonable to propose that $2 \cdot$ TEMPO and $\mathrm{Ph}_{2} \mathrm{Zn}$ equilibrate in the solid state with the simple Lewis acid-base adduct 2 that is active in the SET process leading to 3 (Fig. 4).

\section{Conclusions}

Investigations of solid-state chemistry reactions under mild conditions have remained both one of the greatest mysteries and one of the most challenging tasks for chemists and materials scientists. We demonstrated that mechanochemical and slow-chemistry processes can be used as efficient tools to control the outcome of organometallic radical reactions. Moreover, in our opinion, the reported studies are a significant advance in molecular solid-state chemistry and should aid in unlocking the potential of radical slow-chemistry reactions as a novel tool for the preparation of desired products. At this stage with little knowledge of the mechanisms of the titular solidstate transformations, the best approach to extending this idea would seemingly be through trial and error. Further work in this regard is currently underway in our laboratory.

\section{Experimental}

$t \mathrm{Bu}_{2} \mathrm{Zn}$ was prepared according to literature procedure ${ }^{48}$ under an argon atmosphere using standard Schlenk techniques. $\mathrm{Ph}_{2} \mathrm{Zn}$ and all other reagents were of commercial grade obtained from Sigma-Aldrich Co. The solvents were carefully dried and distilled under a nitrogen atmosphere prior to use. TEMPO was sublimed and stored under an argon atmosphere.

\section{$\left[t \operatorname{BuZn}\left(\mu-\text { TEMPO}^{*}\right)\right]_{2}\left(1_{2}\right)$}

Solution. An orange solution of TEMPO ( $2 \mathrm{mmol}, 0.312 \mathrm{~g})$ in toluene $(2.7 \mathrm{~mL})$ was added dropwise to a stirred solution of $t \mathrm{Bu}_{2} \mathrm{Zn}(1 \mathrm{mmol}, 0.180 \mathrm{~g})$ in toluene $(8 \mathrm{~mL})$ at $-78{ }^{\circ} \mathrm{C}$. A suspension of white solids in colourless solution was formed. The mixture was warmed to RT resulting in a colourless clear solution. After $24 \mathrm{~h}$ at $-15{ }^{\circ} \mathrm{C}$ colourless crystals of 12 deposited from this solution (78\%). ${ }^{1} \mathrm{H}$ NMR (benzene- $d_{6}, 400 \mathrm{MHz}, 25{ }^{\circ} \mathrm{C}$, ppm): $\delta 1.50$ (s, 9H; $\left.\mathrm{ZnC}\left(\mathrm{CH}_{3}\right)_{3}\right), 1.42-1.37$ (br. m, $4 \mathrm{H} ; \beta-\mathrm{CH}_{2}$ ), 1.30-1.23 (br. m, 2H; $\left.\gamma-\mathrm{CH}_{2}\right), 1.18$ (s, $\left.12 \mathrm{H} ; \mathrm{C}\left(\mathrm{CH}_{3}\right)_{2}\right) .{ }^{13} \mathrm{C}\left\{{ }^{1} \mathrm{H}\right\}$ NMR (benzene- $\left.d_{6}, 125 \mathrm{MHz}, 25{ }^{\circ} \mathrm{C}, \mathrm{ppm}\right): \delta 58.87\left(\mathrm{C}\left(\mathrm{CH}_{3}\right)_{2}\right)$, $40.49\left(\beta-\mathrm{CH}_{2}\right), 34.02\left(\mathrm{C}\left(\mathrm{CH}_{3}\right)_{2}\right), 25.50\left(\mathrm{C}\left(\mathrm{CH}_{3}\right)_{3}\right), 17.76\left(\gamma-\mathrm{CH}_{2}\right)$. $\mathrm{C}, \mathrm{H}, \mathrm{N}$ analysis (\%) calcd for $\mathrm{C}_{22} \mathrm{H}_{46} \mathrm{~N}_{2} \mathrm{O}_{2} \mathrm{Zn}_{2}$ : C 52.70, $\mathrm{H} 9.25, \mathrm{~N}$ 5.59; found: C 52.73, H 9.22, N 5.55.
Mechanochemistry. TEMPO $(2.4 \mathrm{mmol}, 0.376 \mathrm{~g})$ and $t \mathrm{Bu}_{2} \mathrm{Zn}$ $(1.2 \mathrm{mmol}, 0.448 \mathrm{~g})$ were ground with a glass rod for 20 minutes at $0{ }^{\circ} \mathrm{C}$ in a Schlenk tube until the product mixture became lightbeige in colour and obtained homogeneous paste-like consistency. Then the volatiles were removed in vacuo at $0{ }^{\circ} \mathrm{C}$. The crude product mixture was analysed by PXRD and ${ }^{1} \mathrm{H}$ NMR. The mixture was dissolved in toluene affording colourless crystals in $81 \%$ yield after $24 \mathrm{~h}$ at $-5{ }^{\circ} \mathrm{C}$.

Slow-chemistry. TEMPO $(0.88 \mathrm{mmol}, 0.137 \mathrm{~g})$ and $t \mathrm{Bu}_{2} \mathrm{Zn}$ (0.44 mmol, $0.079 \mathrm{~g}$ ) were gently mixed with a needle in a Schlenk tube at $-30{ }^{\circ} \mathrm{C}$ and then stored at $5{ }^{\circ} \mathrm{C}$ for 24 hours. The colour of the mixture turned from white-orange to white. The volatiles were removed in vacuo at $5{ }^{\circ} \mathrm{C}$. The crude product mixture was analysed by PXRD and ${ }^{1} \mathrm{H}$ NMR spectroscopy. The mixture was dissolved in toluene affording colourless crystals in $77 \%$ yield after $24 \mathrm{~h}$ at $-15^{\circ} \mathrm{C}$.

\section{$\left[\mathrm{Ph}_{2} \mathrm{Zn}\left(\eta^{1}\right.\right.$-TEMPO $) \cdot$ TEMPO $](2 \cdot$ TEMPO $)$}

Solution. An orange solution of TEMPO ( $2 \mathrm{mmol}, 0.312 \mathrm{~g}$ ) in toluene $(2.1 \mathrm{~mL})$ was added to a suspension of $\mathrm{Ph}_{2} \mathrm{Zn}(1 \mathrm{mmol}$, $0.180 \mathrm{~g})$ in toluene $(8 \mathrm{~mL})$ at $\mathrm{RT}$. The clear yellow reaction mixture was stirred at RT for 1 hour and then placed in a freezer. After $24 \mathrm{~h}$ at $-26{ }^{\circ} \mathrm{C}$ yellow crystals suitable for X-ray analysis were obtained in $69 \%$ yield. The isolated yield was lower for a similar reaction conducted for the 1 : 1 molar ratio (ca. 39\%). The paramagnetic nature of the product was confirmed by EPR spectroscopy. Pure compound $2 \cdot$ TEMPO left for over 6 months at $20{ }^{\circ} \mathrm{C}$ under an inert gas atmosphere does not transform into the diamagnetic compound 3. C,H,N analysis (\%) calcd for $\mathrm{C}_{30} \mathrm{H}_{46} \mathrm{~N}_{2} \mathrm{O}_{2} \mathrm{Zn}_{1}$ : C 67.72, $\mathrm{H}$ 8.71, N 5.26; found: C 67.75, H 8.68, $\mathrm{N} 5.24$.

Mechanochemistry. $\mathrm{Ph}_{2} \mathrm{Zn}(0.5 \mathrm{mmol}, 0.110 \mathrm{~g})$ was gently mixed with TEMPO $(1.0 \mathrm{mmol}, 0.156 \mathrm{~g})$ at $20^{\circ} \mathrm{C}$ and transferred into an agate ball mill. The mixture was milled for a total of 15 minutes (25 Hz, 1 agate ball) in three intervals (with 3 minute breaks, to prevent excessive heating). The colour of the mixture turned yellow. The crude product was analysed by PXRD. No trace of the 3 phase was observed in the PXRD pattern of the postreaction mixture regardless of the process conditions (prolonged time (over 1 hour in total) and higher frequency of milling).

Slow-chemistry. $\mathrm{Ph}_{2} \mathrm{Zn}(0.5 \mathrm{mmol}, 0.110 \mathrm{~g})$ was gently mixed with TEMPO (1.0 mmol, $0.156 \mathrm{~g}$ ) with a needle and stored under an inert gas atmosphere at $20^{\circ} \mathrm{C}$ for 5 days. The colour of the mixture turned yellow. The crude product was analysed by PXRD.

\section{$\left[\operatorname{PhZn}\left(\mu_{2}-\right.\right.$ TEMPO$\left.\left.^{*}\right)\right]\left[\operatorname{PhZn}\left(\mu_{2}-\eta^{1}: \eta^{1}-\right.\right.$ TEMPO$\left.\left.^{*}\right)\right](3)$}

Solution. An orange solution of TEMPO (0.8 mmol, $0.125 \mathrm{~g})$ in toluene $(0.8 \mathrm{~mL})$ was added to a suspension of $\mathrm{Ph}_{2} \mathrm{Zn}(0.8$ mmol, $0.144 \mathrm{~g})$ in toluene $(5 \mathrm{~mL})$ at RT. The clear yellow reaction mixture was stirred at RT for 21 days. After $24 \mathrm{~h}$ at -26 ${ }^{\circ} \mathrm{C}$ colourless crystals suitable for X-ray analysis deposited (isolated yield $24 \%$ ). ${ }^{1} \mathrm{H}$ NMR (benzene- $d_{6}, 500 \mathrm{MHz}, 25{ }^{\circ} \mathrm{C}$, ppm): $\delta 8.01\left(\mathrm{dd},{ }^{3} J=7.82 \mathrm{~Hz},{ }^{4} J=1.35 \mathrm{~Hz}, 2 \mathrm{H}, o-\mathrm{CH}_{(\mathrm{ar})}\right), 7.42$ $\left(\mathrm{t}, 2 \mathrm{H}, J=7.4 \mathrm{~Hz}, m-\mathrm{C} H_{(\mathrm{ar})}\right), 7.30\left(\mathrm{tt}, 1 \mathrm{H},{ }^{3} \mathrm{~J}=7.4 \mathrm{~Hz},{ }^{4} J=1.34\right.$ 
$\left.\mathrm{Hz}, p-\mathrm{CH}_{(\mathrm{ar})}\right), 1.47$ (br m, 4H, $\beta-\mathrm{CH}_{2}$ (TEMPO-ring)), 1.28 (s, $\left.12 \mathrm{H}, \mathrm{C}\left(\mathrm{CH}_{3}\right)_{2}\right), 1.22$ (m, 2H, $\gamma-\mathrm{CH}_{2}$ (TEMPO-ring)). ${ }^{13} \mathrm{C}\left\{{ }^{1} \mathrm{H}\right\}$

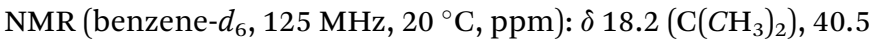
(TEMPO-ring), $41.0\left(\mathrm{C}\left(\mathrm{CH}_{3}\right)_{2}\right), 59.2$ (TEMPO-ring). $\mathrm{C}, \mathrm{H}, \mathrm{N}$ analysis (\%) calcd for $\mathrm{C}_{36} \mathrm{H}_{72} \mathrm{~N}_{4} \mathrm{O}_{4} \mathrm{Zn}_{2}$ : C 57.21, H 9.60, N 7.41; found: C 57.28, $\mathrm{H}$ 9.55, N 7.40.

Slow-chemistry. TEMPO (1.22 mmol, $0.190 \mathrm{~g})$ and $\mathrm{Ph}_{2} \mathrm{Zn}$ $(1.22 \mathrm{mmol}, 0.267 \mathrm{~g})$ were gently mixed with a glass rod in a Schlenk tube under an inert gas atmosphere at $20{ }^{\circ} \mathrm{C}$. The mixture was stored for 21 days at $20{ }^{\circ} \mathrm{C}$ and the progress of the process was monitored by PXRD. The colour of the mixture turned from yellowish to white. Then the mixture was dissolved in toluene. After $24 \mathrm{~h}$ at $-26^{\circ} \mathrm{C}$ colourless crystals of 3 deposited (isolate yield $92 \%$ ). The nature of the product was confirmed by ${ }^{1} \mathrm{H}$ NMR spectroscopy. We note that the slow-chemistry process occurs regardless of whether the substrates were initially gently mixed or ground. However, the initial treatment of the mixture drastically changes the evolution of its PXRD patterns over time (see Fig. S11 and S12† to compare the PXRD patterns of the initially ground and mixed mixtures). Prolonged grinding of the reaction mixture (conducted with 3 minute breaks to prevent excessive heating) results in a mixture of $\mathrm{Ph}_{2} \mathrm{Zn}$ and $2 \cdot$ TEMPO. It is noteworthy that prolonged uninterrupted grinding results in intensive heating of the reaction mixture.

\section{Conflicts of interest}

There are no conflicts to declare.

\section{Acknowledgements}

The authors gratefully acknowledge the financial support of the Foundation for Polish Science TEAM Program co-financed by the European Union under the European Regional Development Fund TEAM/2016-2/14 and the support of the National Science Centre 2015/19/N/ST5/02194. We are grateful to Dr Krzysztof Kruczała and Prof. Zbigniew Sojka for the EPR measurements and Prof. Zbigniew Ochal for GC measurements.

\section{Notes and references}

\$ Bearing in mind that TEMPO melts at approximately $40{ }^{\circ} \mathrm{C}$, we conducted an experiment between an equimolar mixture of $\mathrm{Ph}_{2} \mathrm{Zn}$ and TEMPO at $40{ }^{\circ} \mathrm{C}$. According to PXRD analysis, the reaction gives a mixture of $2 \cdot$ TEMPO and $\mathrm{Ph}_{2} \mathrm{Zn}$ within 30 minutes, which then after 4 days at $40{ }^{\circ} \mathrm{C}$ gives 3 and $\mathrm{PhPh}$ in excellent yield (for details see Fig. S24). We assume that prolonged (days) grinding will lead to the same results as the simple thermal experiment described above, although as a reaction in the melted phase it should no longer be considered as mechanochemistry.

1 D. Braga and F. Grepioni, Angew. Chem., Int. Ed., 2004, 43, 4002-4011.

2 V. Boldyrev and K. Tkáčová, J. Mater. Synth. Process., 2000, 8, 121-132.

3 S. L. James, C. J. Adams, C. Bolm, D. Braga, P. Collier, T. Friščic, F. Grepioni, K. D. M. Harris, G. Hyett, W. Jones, A. Krebs, J. Mack, L. Maini, A. G. Orpen, I. P. Parkin,
W. C. Shearouse, J. W. Steed and D. C. Waddell, Chem. Soc. Rev., 2011, 41, 413-447.

4 Themed Issue: Mechanochemistry, Chem. Soc. Rev., 2013, 42, 7487-7740.

5 J.-L. Do and T. Friščić, ACS Cent. Sci., 2017, 3, 13-19.

6 A. Stolle, T. Szuppa, S. E. S. Leonhardt and B. Ondruschka, Chem. Soc. Rev., 2011, 40, 2317-2329.

7 J. L. Howard, Q. Cao and D. L. Browne, Chem. Sci., 2018, 9, 3080-3094.

8 G.-W. Wang, Chem. Soc. Rev., 2013, 42, 7668-7700.

9 D. Tan and T. Friščić, Eur. J. Org. Chem., 2018, 2018, 18-33.

10 J. Andersen and J. Mack, Green Chem., 2018, 20, 1435-1443.

11 D. Tan and F. García, Chem. Soc. Rev., 2019, 48, 2274-2292.

12 N. R. Rightmire and T. P. Hanusa, Dalton Trans., 2016, 45, 2352-2362.

13 J. Lewiński, M. Dutkiewicz, M. Lesiuk, W. Śliwiński, K. Zelga, I. Justyniak and J. Lipkowski, Angew. Chem., Int. Ed., 2010, 49, 8266-8269.

14 J. G. Hernández, I. S. Butler and T. Friščić, Chem. Sci., 2014, 5, 3576-3582.

15 J. Li, C. Nagamani and J. S. Moore, Acc. Chem. Res., 2015, 48, 2181-2190.

16 N. Willis-Fox, E. Rognin, T. A. Aljohani and R. Daly, Chem, 2018, 4, 2499-2537.

17 D. Prochowicz, K. Sokołowski, I. Justyniak, A. Kornowicz, D. Fairen-Jimenez, T. Friščić and J. Lewiński, Chem. Commun., 2015, 51, 4032-4035.

18 K. Užarević, T. C. Wang, S.-Y. Moon, A. M. Fidelli, J. T. Hupp, O. K. Farha and T. Friščić, Chem. Commun., 2016, 52, 2133-2136.

19 D. Prochowicz, M. Franckevičius, A. M. Cieślak, S. M. Zakeeruddin, M. Grätzel and J. Lewiński, J. Mater. Chem. A, 2015, 3, 20772-20777.

20 P. Pal, S. Saha, A. Banik, A. Sarkar and K. Biswas, Chem.-Eur. J., 2018, 24, 1811-1815.

21 D. J. Kubicki, D. Prochowicz, A. Hofstetter, M. Saski, P. Yadav, D. Bi, N. Pellet, J. Lewiński, S. M. Zakeeruddin, M. Grätzel and L. Emsley, J. Am. Chem. Soc., 2018, 140, 3345-3351.

22 M. Saski, D. Prochowicz, W. Marynowski and J. Lewiński, Eur. J. Inorg. Chem., 2019, 2680-2684.

23 M. J. Rak, T. Friščić and A. Moores, Faraday Discuss., 2014, 170, 155-167.

24 M. Y. Malca, H. Bao, T. Bastaille, N. K. Saadé, J. M. Kinsella, T. Friščić and A. Moores, Chem. Mater., 2017, 29, 7766-7773.

25 A. Moores, Current Opinion in Green and Sustainable Chemistry, 2018, 12, 33-37.

26 P. Krupiński, A. Kornowicz, K. Sokołowski, A. M. Cieślak and J. Lewiński, Chem.-Eur. J., 2016, 22, 7817-7823.

27 Y. Li, N. L. Haworth, L. Xiang, S. Ciampi, M. L. Coote and N. Tao, J. Am. Chem. Soc., 2017, 139, 14699-14706.

28 P. Iversen and D. J. Lacks, J. Electrost., 2012, 70, 309-311.

29 T. Urbański, Nature, 1967, 216, 577-578.

30 M. K. Beyer and H. Clausen-Schaumann, Chem. Rev., 2005, 105, 2921-2948.

31 M. M. Caruso, D. A. Davis, Q. Shen, S. A. Odom, N. R. Sottos, S. R. White and J. S. Moore, Chem. Rev., 2009, 109, 57555798. 
32 B. Baytekin, H. T. Baytekin and B. A. Grzybowski, Angew. Chem., Int. Ed., 2014, 53, 6946-6950.

33 H. T. Baytekin, B. Baytekin and B. A. Grzybowski, Angew. Chem., Int. Ed., 2012, 51, 3596-3600.

34 H. T. Baytekin, B. Baytekin, T. M. Hermans, B. Kowalczyk and B. A. Grzybowski, Science, 2013, 341, 1368-1371.

35 A. M. Belenguer, G. I. Lampronti, D. J. Wales and J. K. M. Sanders, J. Am. Chem. Soc., 2014, 136, 16156-16166.

36 K. Užarević, I. Halasz and T. Friščić, J. Phys. Chem. Lett., 2015, 6, 4129-4140.

37 X. Lim, Nature, 2015, 524, 20-21.

38 M. J. Cliffe, C. Mottillo, R. S. Stein, D.-K. Bučar and T. Friščić, Chem. Sci., 2012, 3, 2495-2500.

39 F. Nudelman and N. A. J. M. Sommerdijk, Angew. Chem., Int. Ed., 2012, 51, 6582-6596.

40 C. Mottillo, Y. Lu, M.-H. Pham, M. J. Cliffe, T.-O. Do and T. Friščić, Green Chem., 2013, 15, 2121-2131.

41 F. Qi, R. S. Stein and T. Friščić, Green Chem., 2014, 16, 121132.

42 C. Mottillo and T. Friščić, Molecules, 2017, 22, 144-181.

43 A. Grirrane, I. Resa, A. Rodriguez, E. Carmona, E. Alvarez, E. Gutierrez-Puebla, A. Monge, A. Galindo, D. del Río and R. A. Andersen, J. Am. Chem. Soc., 2007, 129, 693-703.

$44 \mathrm{~K}$. Budny-Godlewski, D. Kubicki, I. Justyniak and J. Lewiński, Organometallics, 2014, 33, 5093-5096.

45 M. Kubisiak, K. Zelga, W. Bury, I. Justyniak, K. BudnyGodlewski, Z. Ochal and J. Lewiński, Chem. Sci., 2015, 6, 3102-3108.

46 P. Jochmann and D. W. Stephan, Chem. Commun., 2014, 50, 8395-8397.

47 For selected examples of the role of SET in organozinc chemistry, see: (a) E. Wissing, S. van der Linden, E. Rijnberg, J. Boersma, W. J. J. Smeets, A. L. Spek and
G. van Koten, Organometallics, 1994, 13, 2602-2608; (b) J. Lewiński, W. Śliwiński, M. Dranka, I. Justyniak and J. Lipkowski, Angew. Chem., Int. Ed., 2006, 45, 4826-4829; (c) J. Lewiński, K. Suwała, M. Kubisiak, Z. Ochal, I. Justyniak and J. Lipkowski, Angew. Chem., Int. Ed., 2008, 47, 7888-7891; (d) I. Dranka, M. Kubisiak, I. Justyniak, M. Lesiuk, D. Kubicki and J. Lewiński, Chem.-Eur. J., 2011, 17, 12713-12721; (e) E. Folkertsma, S. H. Benthem, J. T. B. H. Jastrzebski, M. Lutz, M.-E. Moret and R. J. M. Klein Gebbink, Eur. J. Inorg. Chem., 2018, 1167-1175. 48 J. Lewiński, M. Dranka, W. Bury, W. Śliwiński, I. Justyniak and J. Lipkowski, J. Am. Chem. Soc., 2007, 129, 3096-3098.

49 G. Wittig, F. J. Meyer and G. Lange, Justus Liebigs Ann. Chem., 1951, 571, 167-201.

50 P. R. Markies, G. Schat, O. S. Akkerman, F. Bickelhaupt, W. J. J. Smeets and A. L. Spek, Organometallics, 1990, 9, 2243-2247.

51 D. R. Armstrong, L. Balloch, J. J. Crawford, B. J. Fleming, L. M. Hogg, A. R. Kennedy, J. Klett, R. E. Mulvey, C. T. O'Hara, S. A. Orr and S. D. Robertson, Chem. Commun., 2012, 48, 1541-1543.

52 For selected examples of TEMPO* anion coordination modes in organozinc chemistry, see: ref. 44 and 46, and (a) G. C. Forbes, A. R. Kennedy, R. E. Mulvey and P. J. A. Rodger, Chem. Commun., 2001, 1400-1401; (b) Z. Zhu, J. C. Fettinger, M. M. Olmstead and P. P. Power, Organometallics, 2009, 28, 2091-2095; (c) J. Francos, A. R. Kennedy and C. T. O'Hara, Dalton Trans., 2016, 45, 6222-6233.

53 J. L. Russ, J. Gu, K.-H. Tsai, T. Glass, J. C. Duchamp and H. C. Dorn, J. Am. Chem. Soc., 2007, 129, 7018-7027.

54 M. R. Haneline and F. P. Gabbaï, Inorg. Chem., 2005, 44, 6248-6255. 